\title{
Incidental Finding of Elevated Serum Cartilage Oligomeric Matrix Protein (sCOMP) in Knee Osteoarthritis Patient with Undiagnosed Colon Cancer: A Case Report
}

Yose Waluyo'

Gita Vita Soraya ${ }^{2}$

Susanto H Kusuma $\mathbb{D}^{3}$

Faradilla Anwar ${ }^{3}$

Insani Nanda Wahyuni ${ }^{4}$

'Department of Physical Medicine and Rehabilitation, Faculty of Medicine, Hasanuddin University, Makassar, Indonesia; ${ }^{2}$ Department of Biochemistry, Faculty of Medicine, Hasanuddin University, Makassar, Indonesia; ${ }^{3}$ Siloam Hospitals, Makassar, Indonesia;

${ }^{4}$ Cerebellum Clinic, Makassar, Indonesia
Background: The clinical utility of cartilage oligomeric matrix protein (COMP) as a diagnostic and prognostic biomarker is currently under intense study. COMP has been associated primarily with musculoskeletal disorders such as rheumatoid and osteoarthritis (OA) or muscular and ligament trauma. Aside from its established role as a biomarker of arthritis, an increasing number of studies have also suggested the role of COMP in tumorigenesis, based on findings of its expression in breast, prostate, and colon cancers.

Case Presentation: We described the case of a 61-year-old man with knee osteoarthritis and was prescribed physical therapy and a course of prolotherapy injection. We found elevated sCOMP levels in our patient (twice higher than average). After a month of followup, he was diagnosed with colorectal cancer.

Conclusion: It makes us wonder about other conditions of the patients. There is no standard COMP parameter to differentiate OA patients from colorectal cancer patients, but it considers the increase is higher in colorectal cancer patients. We suggest to clinicians who use the COMP level to monitor OA condition to be aware of other conditions when the level is much higher than average OA patients.

Keywords: cartilage oligomeric matrix protein, knee osteoarthritis, colorectal cancer

\section{Introduction}

The clinical utility of cartilage oligomeric matrix protein (COMP) as a diagnostic and prognostic biomarker is currently under intense study. The 524$\mathrm{kD}$ pentameric glycoprotein is dominantly expressed in cartilage and surrounding tissues ${ }^{1,2}$ and hence has been associated primarily with musculoskeletal disorders such as rheumatoid and osteoarthritis (OA), or muscular and ligament trauma. In these inflammatory musculoskeletal disorders, COMP fragmentation occurs due to extracellular matrix destruction, ${ }^{3}$ leading to subsequent COMP released into the synovial fluid and bloodstream. Therefore, serum COMP concentrations higher than the average value found in healthy populations $(>5$ $\mu \mathrm{g} / \mathrm{mL}$ ) have been shown to indicate cartilaginous damage in cases of osteoarthritis and rheumatoid arthritis. ${ }^{4-6}$ Recent meta-analysis has consistently shown higher serum COMP in OA patients compared to normal populations and can even be utilized to distinguish OA severity. ${ }^{7,8}$
Correspondence: Yose Waluyo Department of Physical Medicine and Rehabilitation, Faculty of Medicine, Hasanuddin University, Makassar, Indonesia

Email yosewaluyo00@gmail.com 
Aside from its established role as a biomarker of arthritis, an increasing number of studies have also suggested the role of COMP in tumorigenesis, based on findings of its expression in breast, prostate, and colon cancers. $^{9-11}$ Recent studies have attempted to explore the basis of this association, elucidating the role of COMP in the activation of the PI3K/Akt/mTOR/P70S6K ${ }^{12,13}$ and the Notch3 pathway. ${ }^{14}$

Herein, we report an incidental finding of elevated COMP in a case within our 84-patient cohort of OA patients. The patients were tested for COMP as part of the workup for the dextrose prolotherapy injection regimen in Cerebellum Clinic in Makassar, Indonesia. Coincidentally, the patient that we describe below has shown higher COMP levels in comparison to the average level of the cohort. All COMP levels were tested at the Hasanuddin University Medical Research Centre (HUMRC) Laboratories. Blood samples were obtained by using the venipuncture technique based on WHO standards. Samples are then stored in a freezer with temperature $-80^{\circ} \mathrm{C}$. We used Bioassay Technology Laboratory Human COMP Elisa Kit Cat. No E1486Hu to measured COMP level in samples' serum. Subjects' guardian has given their written informed consent to publish their case (including publication of images).

\section{Case Presentation}

A 61-year-old man came to our clinic with a complaint of knee pain for 3 years. After physical and radiologic examination, knee OA was established diagnosed, and the patient was prescribed physical therapy and a course of prolotherapy injection. We assessed the COMP level and the functional outcome as an accompanying workup for this patient's management.

We found that the COMP level of this patient was $1965.05 \mathrm{pg} / \mathrm{mL}$, which was much higher than the average level of the group $(804.22 \mathrm{pg} / \mathrm{mL})$. At the first consultation, the patient did not have any complaint that leads to cancer symptoms such as progressive low weight or digestive bleeding. However, at the second schedule of his prolotherapy injection, he could not come due to haematochezia complaints about 3 days. We consulted him for a colonoscopy and we found easily bleed mass at approximately $15 \mathrm{~cm}$ from the anal valve and covered intestinal lumen as seen in Figure 1. Then, we did pathology examination, and adenocarcinoma rectum was found. The patient has been offered to perform surgery, but he refused and chose to have chemotherapy. After some chemotherapy sessions, the patient died due to his disease.

\section{Discussion and Conclusion}

Cartilage oligomeric matrix protein (COMP) or thrombospondin 5 is an extracellular matrix glycoprotein with $524 \mathrm{kDa}$ molecular weight. COMP has five identical subunits, which have 755 amino acids each. COMP forms homopentamers induced by an N-terminal coiled-coil domain, followed by epidermal growth factor-like domains (EGF), eight thrombospondin type II repeats, and a C-terminal COMP (TC) domain. ${ }^{15,16}$ COMP was initially identified as a component of cartilage and has been highly expressed in both developing and mature cartilage as well as in tendon and ligament. ${ }^{17}$

COMP has a role as diagnostic and prognostic biomarkers for arthritis, including knee osteoarthritis. ${ }^{5,15}$ Higher

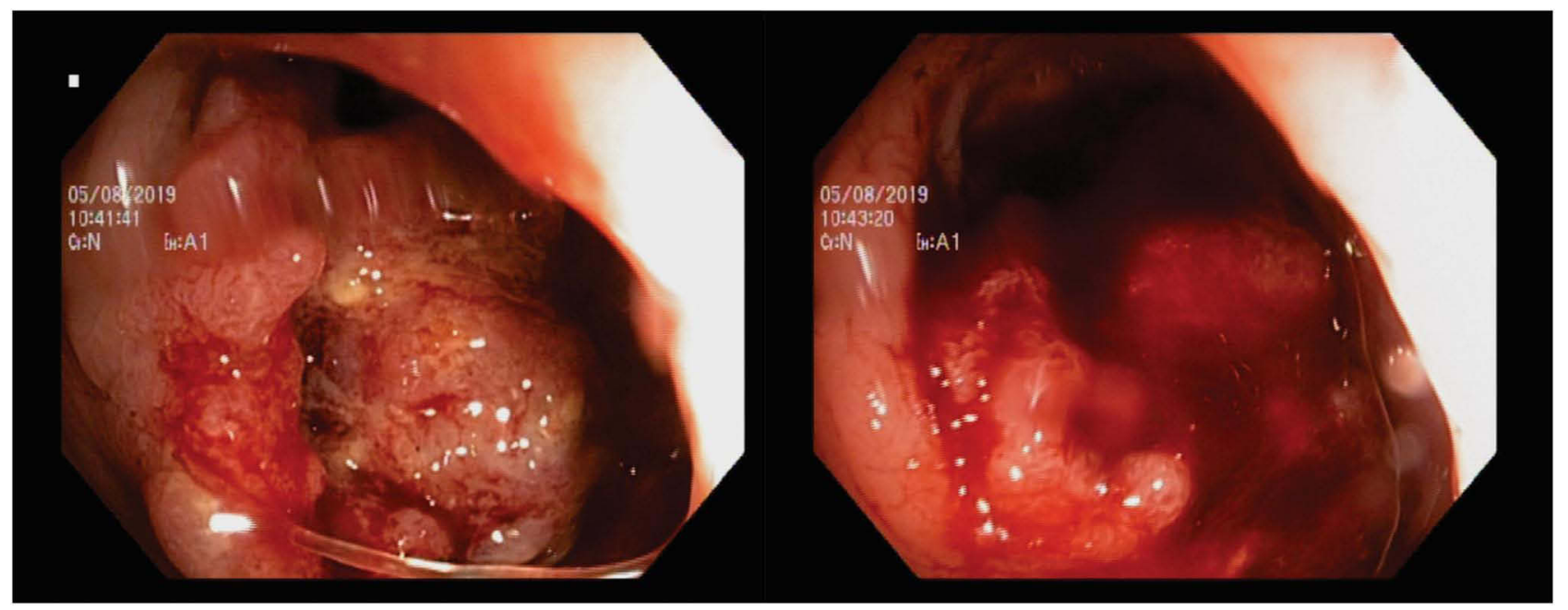

Figure I Colonoscopy findings. We found easily bleed mass at approximately $15 \mathrm{~cm}$ from the anal valve covering the intestinal lumen. 
serum COMP has a linear correlation with the severity of KOA. $^{7,18}$ Patients with effusion, synovitis, and longer osteophytes in the knee have a higher concentration of COMP biomarker in serum than those without OA inflammatory indicator. ${ }^{19}$ The serum COMP level remains significantly high in the first 3 years of disease duration. ${ }^{20}$

Although extensive evidence is available on the association between serum COMP levels and active joint diseases such as RA and $\mathrm{OA},{ }^{6,21}$ the relationship is less established with tumors. Until now, the role of COMP in carcinogenesis is still under investigation, with evidence pointing to its role in the activation of various tumorigenic pathways. The presence of this case of colon cancer in our cohort sparks particular interest due to the high serum COMP levels found in both compared to the already elevated average of the OA cohort.

Unfortunately, knowledge on the diagnostic and prognostic utility of the serum COMP marker in colon cancer is still limited. A previous study based on immunohistochemistry has shown its prognostic utility in metastatic stages of breast cancer. ${ }^{22}$

Liu et al observed that decreased COMP inhibited cell proliferation. Contrasting results were found in cells overexpressing COMP. As mentioned above, the expression COMP is positively correlated with the PI3K/Akt/mTOR/ p70S6K pathway activation. COMP can activate the PI3K pathway by activating epidermal growth factor receptors (EGFRs) that promote cell proliferation and survival. PI3K promotes Akt translocation and activation. Activation of Akt in response to COMP stimulation increases cell growth and proliferation via the mTOR pathway. In the TORCI complex, mTOR phosphorylates its downstream effector, p70 S6K, to induce protein translation. Also, Akt enhances cell survival by directly deactivating the pro-apoptotic protein Bax and activating the anti-apoptotic protein Bcl-2. ${ }^{11}$

COMP is also involved in the malignant progression of colorectal cancer, and its mechanism may be related to the expression of COMP-induced apoptosis inhibitors and inhibition of apoptosis in colorectal cancer cells. Besides, COMP binds directly to thrombin, inhibits thrombin activity, and prevents physiological hemostasis and thrombosis. ${ }^{23}$ This COMP feature may also increase the risk of colorectal cancer metastases. Stromal cells inhibit tumor metastasis through the extracellular matrix barrier (ECM), through which tumor cells must break through to metastasize. ${ }^{9}$ Studies have shown that COMP can degrade tumor cells of the surrounding ECM stroma and enhance epithelial-mesenchymal translocation (EMT) by increasing MMP9 expression, thereby promoting tumor metastasis. ${ }^{9}$

It makes us wonder about other conditions of the patients. There is no standard COMP parameter to differentiate OA patients from colorectal cancer patients, but it considers the increase is higher in colorectal cancer patients. We suggest to clinicians who use the COMP level to monitor OA condition to be aware of other conditions when the level is much higher than average OA patients.

\section{Statement of Ethics}

Ethical approval was obtained from the Faculty of Medicine Hasanuddin University Ethics Committee (protocol number UH19100814).

\section{Consent for Publication}

Written informed consent was obtained from the patients' guardian to publish this case report and any accompanying images, also approved by the Faculty of Medicine Hasanuddin University Ethics Committee.

\section{Author Contributions}

All authors made a significant contribution to the work reported, whether that is in conception, study design, execution, acquisition of data, analysis and interpretation, or in all these areas; took part in drafting, revising or critically reviewing the article; gave final approval of the version to be published; have agreed on the journal to which the article has been submitted; and agree to be accountable for all aspects of the work.

\section{Funding}

This case report did not receive any specific grant from funding agencies in the public, commercial, or not-forprofit sectors. The study was funded by independent cost.

\section{Disclosure}

The authors report no conflicts of interest in this work.

\section{References}

1. Newton G, Weremowicz S, Morton CC, et al. Characterization of human and mouse cartilage oligomeric matrix protein. Genomics. 1994;24(3):435-439. doi:10.1006/geno.1994.1649

2. Halász K, Kassner A, Mörgelin M, Heinegard D. COMP acts as a catalyst in collagen fibrillogenesis. $J$ Biol Chem. 2007;282 (43):31166-31173. doi:10.1074/jbc.M705735200

3. Oldebrand ESKI, Ekman S, En LMH. Cartilage oligomeric matrix protein neoepitope in the synovial fluid of horses with acute lameness: a new biomarker for the early stages of osteoarthritis. Equine Veterinary J. 2017;49(5):662-667. doi:10.1111/evj.12666 
4. Wis M, Jab B. Serum cartilage oligomeric matrix protein (COMP) in rheumatoid arthritis and knee osteoarthritis. Clinical Rheumatol. 2005:278-284. Doi:10.1007/s10067-004-1000-x

5. Wisłowska M, Jabłońska B. Serum cartilage oligomeric matrix protein (COMP) in rheumatoid arthritis and knee osteoarthritis. Clin Rheumatol. 2005;24(3):278-284. doi:10.1007/s10067-004-1000-x

6. Neidhart M, Hauser N, Paulsson M, Dicesare PE, Michel BA, Häuselmann HJ. Small fragments of cartilage oligomeric matrix protein in synovial fluid and serum as markers for cartilage degradation. Br J Rheumatol. 1997;36(11):1151-1160. doi:10.1093/ rheumatology/36.11.1151

7. $\mathrm{Bi} \mathrm{X}$. Correlation of serum cartilage oligomeric matrix protein with knee osteoarthritis diagnosis: a meta-analysis. J Orthop Surg Res. 2018;13(1):262. doi:10.1186/s13018-018-0959-y

8. Zhang J. Meta-analysis of serum C-reactive protein and cartilage oligomeric matrix protein levels as biomarkers for clinical knee osteoarthritis. Clinical Rheumatol. 2018:1-6. Doi:10.1186/s12891-018-1932-y

9. Englund E, Bartoschek M, Reitsma B, et al. Cartilage oligomeric matrix protein contributes to the development and metastasis of breast cancer. Oncogene. 2016;35(43):5585-5596. doi:10.1038/onc.2016.98

10. Englund E, Canesin G, Papadakos KS, et al. Cartilage oligomeric matrix protein promotes prostate cancer progression by enhancing invasion and disrupting intracellular calcium homeostasis. Oncotarget. 2017;8 (58):98298-98311. doi:10.18632/oncotarget.21176

11. Liu T, Liu X, Zhang M, et al. Cartilage oligomeric matrix protein is a prognostic factor and biomarker of colon cancer and promotes cell proliferation by activating the Akt pathway. J Cancer Res Clin Oncol. 2018;144(6):1049-1063. doi:10.1007/s00432-018-2626-4

12. Guertin DA, Sabatini DM. Defining the Role of mTOR in Cancer. Cancer Cell. 2007;12(1):9-22. doi:10.1016/j.ccr.2007.05.008

13. Mayer IA, Arteaga CL. The PI3K/AKT Pathway as a Target for Cancer Treatment. Annu Rev Med. 2016;67(1):11-28. doi:10.1146/ annurev-med-062913-051343

14. Papadakos KS, Bartoschek M, Rodriguez C, et al. Cartilage Oligomeric Matrix Protein initiates cancer stem cells through activation of Jagged1-Notch3 signaling. Matrix Biol. 2019;81:107-121. doi:10.1016/j.matbio.2018.11.007
15. Tseng S, Reddi AH, Di Cesare PE. Cartilage Oligomeric Matrix Protein (COMP): a Biomarker of Arthritis. Biomark Insights. 2009;4:33-44. doi:10.4137/BMI.S645

16. Gebauer JM, Köhler A, Dietmar H, et al. COMP and TSP-4 interact specifically with the novel GXKGHR motif only found in fibrillar collagens. Sci Rep. 2018;8(1):17187. doi:10.1038/ s41598-018-35447-8

17. Kipnes J, Carlberg AL, Loredo GA, Lawler J, Tuan RS, Hall DJ. Effect of cartilage oligomeric matrix protein on mesenchymal chondrogenesis in vitro. Osteoarthr Cartil. 2003;11(6):442-454. doi:10. 1016/S1063-4584(03)00055-4

18. Vilím V, Olejárová M, Macháček S, Gatterová J, Kraus V, Pavelka K. Serum levels of cartilage oligomeric matrix protein (COMP) correlate with radiographic progression of knee osteoarthritis. Osteoarthr Cartil. 2002;10(9):707-713. doi:10.1053/joca.2002.0819

19. Živanović S, Petrović Rackov L, Živanović A, Jevtić M, Nikolić S, Kocić S. Cartilage Oligomeric Matrix Protein - inflammation biomarker in knee osteoarthritis. Bosn J Basic Med Sci. 2011;11(1):27. doi:10.17305/bjbms.2011.2619

20. Verma P, Dalal K. Serum cartilage oligomeric matrix protein (COMP) in knee osteoarthritis: a novel diagnostic and prognostic biomarker. J Orthop Res. 2013;31(7):999-1006. doi:10.1002/jor.22 324

21. Saxne T, Heinegård D. Cartilage oligomeric matrix protein: a novel marker of cartilage turnover detectable in synovial fluid and blood. Rheumatology. 1992;31(9):583-591. doi:10.1093/rheumatology/31.9. 583

22. Papadakos KS, Darlix A, Jacot W, Blom AM. High levels of cartilage oligomeric matrix protein in the serum of breast cancer patients can serve as an independent prognostic marker. Front Oncol. 2019;9 (OCT). doi:10.3389/fonc.2019.01141

23. Metharom P, Berndt MC. COMP: an endogenous thrombin inhibitor. Blood. 2015;126(7):831-832. doi:10.1182/blood-2015-06-650846
International Medical Case Reports Journal

\section{Publish your work in this journal}

The International Medical Case Reports Journal is an international, peer-reviewed open-access journal publishing original case reports from all medical specialties. Previously unpublished medical posters are also accepted relating to any area of clinical or preclinical science. Submissions should not normally exceed 2,000 words or 4 published pages including figures, diagrams and references. The manuscript management system is completely online and includes a very quick and fair peer-review system, which is all easy to use. Visit http://www.dovepress.com/testimonials.php to read real quotes from published authors. 